AN ACCOUNT OF A CASE

oF

ENCEPHALOID DISEASE

oF

\title{
THE ENDOCARDIUM.
}

BY EDWARD LATHAM ORMEROD, M.B.,

DEMONSTRATOR OF MORBID ANATOMY AT ST. BARTHOLOMEW'S HOSPITAL.

Received December 22nd, 1846-Read February 9th, 1847.

The subject of the following remarks was admitted, in the course of November 1846, into St. Bartholomew's Hospital, under the care of Dr. Roupell, to whom I am indebted for the permission to communicate the case to the Society, and whose attention in investigating all the symptoms is the best guarantee that the imperfections of the diagnosis which constitutes the chief interest of the case did not arise from any carelessness or inaccuracy.

William Pavey, aged 48, extremely weak and emaciated; a man of temperate and steady habits, married three times, having had one child by the second wife, but none by the third, whom he married twenty months ago, was under observation for about the last fortnight of his life. He had always had good health till two years ago, when his right testicle became enlarged, causing him great distress by its weight, and so incapacitating him for work that he submitted to its removal in the early part of August last. The scrotum had not ulcerated, and the wound healed readily after the operation, leaving a neat, firm cicatrix.

There was at this time no suspicion of the disease extend- 
ing further than the testis, and the enlargement of this part was not supposed to be owing to encephaloid disease; but suspicion was aroused by the observation of a soft tumour in the epigastrium, which was noticed while the patient was recovering from the operation. However, in the course of a month he resumed his employment as a warehouseman, but gave it up again, in a few weeks, from sheer debility. A violent attack of diarrhœa about this time completed his prostration, and since then he kept his bed, till his death. He had no pain, but merely extreme weakness, with constipation and occasional vomiting, his food returning unchanged sometimes as much as ten hours after ingestion. He had never suffered from cough nor hæmoptysis, nor anasarca, and there was no enlargement of the superficial veins of the abdomen.

To sustain his strength, and to allay the vomiting which had only existed within ten days previous to his admission, were the indications acted on ; the latter with great success by means of hydrocyanic acid; the former to little purpose, for he died on Nov. 24, twelve days after admission.

The examination of the various organs during life elicited the following facts :--

Beneath the lower end of the left sterno-mastoid muscle was a tumour about as large as a chestnut, which was said to have been only lately noticed.

Respiratory murmur was almost absent, and there was some dullness on percussion beneath the left clavicle; the heart's sounds were loudly transmitted below both clavicles. A systolic murmur was audible at the apex of the heart, of a faintly musical character, and one of a soft blowing character was heard in both the pulmonary artery and the aorta.

In the epigastrium there was a soft tumour, slightly painful on pressure and doubtfully fluctuating, which was said to vary in size at different times. Below and a little to the right a gurgling sensation was communicated to the fingers on making light rapid pressure ; below this, in the right umbilical and lumbar regions, was a large hard tumour, evidently behind the intestines, which gave a clear sound on percus- 
sion everywhere except over the soft epigastric tumour : once only during life was the lumbar tumour dull on percussion.

The urine, the secretion of which had been temporarily suppressed, being examined on the earliest opportunity, was found to be loaded with urates and pus globules, in which last the nuclei were singularly distinct when viewed under the microscope. Let us compare these results with those of the examination of the body after death.

The brain was not examined. The cervical glands were generally enlarged, but apparently healthy, except one mass which lay behind and to the outer side of the left common carotid, and a soft swelling, apparently of a glandular origin, (being the tumour noticed during life,) lying behind the left sterno-mastoid, with the fibres of the scaleni muscles spread over it:- this mass extended on the outer side of the carotid artery, and above and somewhat behind the subclavian artery which crossed its lower end; and was itself traversed in front by the phrenic nerve. It had only loose attachments above and all round; but below, where it sank behind the clavicle, it was firmly attached to the costal, which adhered about the same place to the pulmonary, pleura. On removal, it appeared to be a firm elastic cyst, of about two inches diameter in the long, and one in the shorter, axis. On section, a dirty, purple grumous substance exuded, leaving a thin but strong membranous bag, whose inner wall was rough with adherent particles of the same grumous matter.

The apices of both lungs were adherent by firm old cellular bands; the rest of the left lung was also more or less adherent by looser fibrin, and the pulmonary pleura was in some points thickened. Throughout each apex were scattered numerous small grey-yellow granules, with some chalky nodules (apparently quiescent tubercles or their remains), and the lungs, to the same extent, were largely infiltrated with black pulmonary matter. Elsewhere they were healthy, except near the base of the right, where there were a few raised patches, of about three lines in diameter, and of a dull red colour with a somewhat lighter-coloured border : beneath these the 
substance of the lung was softened to the depth of a line or more.

The heart was of about the natural size, externally healthy, with the exception of a pale spot on the anterior surface of the right ventricle: the walls were thin and flabby, the valves efficient, and all the cavities healthy except that of the right ventricle, which appeared nearly filled up by some roundish masses of a dull red colour and soft consistency, springing from a point corresponding to the pale spot seen on the external surface of the heart: their free rounded extremities were directed towards the pulmonary artery, and the tip of the longer lobule was not more than an inch distant from the lower edge of its valves. Parallel to this, and to its right, lay a similarly-shaped but shorter mass, which was separated from the next mass by the carneæ columnæ giving origin to the chordæ tendineæ for the left flap of the tricuspid valve; so that the next lobule, which was shorter than the two preceding, thicker and somewhat cleft at its free end, projected into the ring of the valves, and, though it might not have actually intervened between the edges of the flaps of the closed valve, it must have interfered with the play of the cordæ tendineæ. Below lay two or three roundish flattened masses extending quite to the apex of the ventricle.

Just about the attachment of the larger masses, the muscular substance of the heart appeared infiltrated with encephaloid matter; but nearer the apex, where the tumours were smaller, the muscular substance of the heart was comparatively, if not quite, free; the masses being attached by roots ramifying among the carneæ columnæ, and adhering to the surface, without actually penetrating into the muscular substance, of the organ.

In the usual situations existed small, rough, red, fibrinous coagula, to which, in colour, though not in consistency, the encephaloid masses bore a great resemblance.

The results of the external examination of the abdomen, after death, were much the same as already noticed during life, except that the tumour in the lumbar region could not be 
so distinctly felt. On reflecting the integuments, which were free from all attachment to the tumour and very thin, the edge of the liver appeared from beneath the right costal cartilages, and was small but healthy; below this was the gallbladder, containing nearly $4 \mathrm{oz}$. of dark bile. Next, on descending towards the pubes, there appeared a large round soft swelling (the epigastric tumour already mentioned), over the front of which the pyloric end of the stomach, the first two portions :of the duodenum, and the pancreas with the superior mesenteric vein, were visible. The colon, corresponding in situation to the place where the gurgling had been felt during life, crossed the abdomen below these, turning up at a sharp angle from the right flank. Below this was a space, over which was spread the peritonæum from the back wall of the abdomen, and part of the mesentery, the small intestines having fallen away into the cavity of the pelvis and the hollow of the flanks on either side.

The tumour was now seen to be a large, imperfectly lobulated mass, of a soft elastic feel and dark purple colour, weighing about 5 lbs., and occupying chiefly the right lumbar region, but extending across the spine into the left also. It was free from all but ordinary cellular attachments to the spine; the left kidney, the pancreas and the duodenum, had contracted no unnatural adhesions to it; and the spleen, which was quite free, was, like the other viscera of the abdomen, perfectly healthy ; the right kidney alone was diseased. This organ was connected very firmly with the tumour by old cellular tissue ; it presented no traces of encephaloid disease, but the surface, beneath the capsule, was ecchymosed in points ; in other points were yellow deposits of pus extending a short way into the cortical structure of the kidney,- the ordinary appearances of suppurative nephritis; and in one place there was a funnel-shaped depression, about four lines in diameter, communicating with the pelvis of the kidney which was filled with pus.

The tumour, on a closer examination, was found to be composed of a soft brain-like matter, closely resembling that in 
the neck, readily exuding on the division and pressure of any of its large lobular masses. The aorta and vena cava ascendens ran through its substance, these two vessels being separated at the upper end of the tumour by a space of two inches. The coats of the artery were healthy, as were also those of the vein at its upper extremity; but the cavity of this vessel was almost obliterated below by loose yellow flocculent masses adhering to its walls : the left common iliac vein was obliterated by a firm laminated coagulum, the right at its entrance into the tumour was ulcerated; and its union with the left iliac, where this vessel had become pervious, to form the cava, was not distinguishable in the softened mass. The lumbar veins were much enlarged but healthy.

Numerous enlarged glands were scattered about in more or less close connection with this tumour. In the track of the right external iliac vein were a few small hard bodies; the corresponding parts on the left side were healthy.

The left testicle was small, and apparently healthy. The right, which Mr. Childs of Fore-street (who had removed it in August) has liberally deposited in the Museum of St. Bartholomew's Hospital, forms a large round ball, the enlargement being chiefly confined to the body of the organ. The cavity of the tunica vaginalis is obliterated by a thin flake of fibrin, adherent on both sides and completely circumscribing the morbid growth, which in one part has perforated the visceral layer of the tunica vaginalis, but is separated by the flake of fibrin from the reflected layer. The substance of the organ is irregularly lobulated, one large lobule having apparently cracked away from the rest, from the effects of the solution in which it has been kept; one or two small yellow spots are to be seen in it, but there is no appearance of softening of the organ.

On examination of the tumours under the microscope, with the assistance of $\mathrm{Mr}$. Paget, that in the heart was found to be made up of a loose opake tissue and granular matter. Of the tissue itself, nothing could be made out satisfactorily; the tumour seemed for the most part composed of granules, 
these being roundish bodies, pale, granular, but much smoother than pus globules, mingled with caudate corpuscles of varying form, and very exactly resembling the awned seeds of some grasses; there were also some cells with nuclei, which were granular, like their parent cells. There were many small flat globules and some crystals, but none of these last were found in the abdominal tumour, which was examined in the recent state. In the testicle, nothing could be clearly made out, the substance seemed to have been so altered by the action of the solution; all that was distinctly discernible being a few globules, such as constituted the mass of the tumours in the heart and abdomen.

The subject of encephaloid disease of the heart and testis has been so lately before the Society, that it seems best to confine the present communication to those parts of the subject on which the case under consideration appears to throw some light; namely, the diagnosis and the mode of origin of the cardiac disease : merely noticing by the way, with regard to the diagnosis of the abdominal affection, how the discovery of pus in the urine, which was so clearly explained after death, led to the rejection of the previously formed and correct opinion, that the lumbar glands were the seat of disease.

The state of the heart was not examined hastily, but more than once with the greatest care, on account of the suspicion that there was medullary disease of the pericardium, - the friction of the hair of the chest under the stethoscope having given rise for the first two days to this suspicion. From the facts elicited it does not appear that any murmur existed at the base of the heart characteristic of the presence of the tumour; for as there was also a murmur in the aorta, it would be unfair to conclude that the murmur in the pulmonary artery arose from the presence of the tumour in the right ventricle;-rather the murmur in both situations arose from a common cause, namely, the condition of the blood. But, considering the position of the tumour in relation to the tricuspid valve, it seems natural to refer the murmur at 
the apex of the heart to imperfection of this valve, caused by the presence of the lobule already alluded to within the circle of the chordæ tendineæ; though the absence of a more exact definition of the situation of the murmur than the general statement of its having been audible at the apex affords, is to be regretted in a case fitted as this was to test the accuracy of particular diagnosis between imperfections of the mitral and the tricuspid valves.

On the subject of the auscultatory signs of encephaloid diseases of the heart, the following brief notice possesses some interest :-in a man aged 45, suffering from cancerous disease of the pylorus, who died in St. Bartholomew's Hospital in the spring of 1846, it was noticed three days before death that the heart's sounds were not clear, though unaccompanied by any murmur : on dissection, it is recorded that there were found $2 \mathrm{oz}$. of blood-red serum in the pericardium, the membrane being highly injected, not coated with any fibrin, but studded, especially about the reflection of the pericardium from the heart to the great vessels, with raised, flattened, yellow bodies, which were about the size of melon seeds, and separate over the face of the ventricles, but larger and almost confluent about the base; similar bodies existed also on the right pleura and in the right crus of the diaphragm. Probably auscultation might have detected a friction sound at a later period when pericarditis had commenced; but certainly the encephaloid disease did not itself give any local signs of its presence, either physical or constitutional. Its existence in the pericardium would have been manifested only by the signs properly referrible to the inflammation which it produced, as in the interior of the heart only by the incidental circumstance of its interfering, as any other foreign body might do, with the heart's action.

It is impossible to read the collection of cases of cancer of the heart presented by Bouillaud (Des Maladies du Cœur, tom. ii. $428,2^{\text {me }}$ ed.), or the more complete summary of Dr. Walshe (On Cancer, p. 368), and not still agree with Dr. Hope (On Diseases of the Heart, p. 355, 3rd ed.), that 
sufficient materials for a history of cancer of the heart have not been collected. The cases just narrated, by showing the uncertainty of the diagnosis, only tend to confirm this remark, and the characteristic symptoms of suffering from this lesion are equally left in obscurity. Indeed, after eliminating the particulars which are common to other forms of disease of the muscular structure or valves of the heart, there are very few left that throw any light at all on the matter : for, to apply to the particular case before us what Dr. Latham remarks in a more general sense, "they have nothing to do with the essence of the tumour in question, and profit us nothing in suggesting any method of cure. They have, in fact, no rational treatment ; and simply for this reason, because they have no essential symptoms."-(Latham on Diseases of the Heart, ii. p. 131.)

We proceed, lastly, to consider the mode in which the cancer had originated in the heart in this particular case. Looking at the history of the case, and the size of the abdominal tumour, it appears probable that the cardiac affection was secondary to the abdominal. And, taking the size of the tumours in the heart itself and the amount of the surrounding morbid changes again as our guide, it would seem that the tumours at the apex were more recent than those nearer the base of the heart. It might be argued with some plausibility from this case by itself, that, whatever the form and mode of connection of the tumours at the apex, such might be inferred to have been at the earliest period of their existence that of the tumours nearer the base, though it was now concealed in their further growth. But we prefer to investigate the matter by showing what light the published cases of endocardial cancer throw on one another.

Of the six cases of endocardial cancer which we are acquainted with, only four are applicable to the present purpose ; the case reported by $\mathbf{M}$. Cruveilhier from M. Payan, if indeed it be a case of cancer at all, and the second of Mr. Prescott Hewett's cases lately communicated to the Society, (Med. Gaz., vol. xxxviii. p. 889,) not exhibiting any very cha- 
racteristic forms of the disease, and the last merely presenting a soft deposit which could be determined to be of a cancerous nature only by the history of the case and microscopic examination. The other four cases of primary disease of the endocardium, - primary as distinguished from cancerous growths, which have perforated the walls of the heart, whether originating in the muscular substance of the heart itself or in any neighbouring part-seem well to illustrate the different stages in the growth of these tumours.

The mode of arrangement presumes an analogy to exist, as suggested by Rokitansky, (Path. Anat., Bd. ii. s. 469,) between cancerous tumours of the endocardium, and the more commonly known globular vegetations of Laennec (Auscult. Mediate, tome iii. p. 344).

But as the analogy, owing to the essential difference between the component particles of the globular vegetations and cancerous matter, is only strictly applicable to the earliest stage, it will be sufficient to observe that these vegetations are supposed to have their origin in spontaneous coagulation of the blood, the result of abnormal conditions of that fluid; the coagula thus formed becoming adherent, by means of pedicles, to the valves or muscular walls of the heart, especially in the tips of the auricles or ventricles.

The cases seem to stand thus : First stands M. Cruveilhier's case, (Anat. Path., liv. 40, pl. 2,) which, considering its origin from the venous sinus, and not from the tip of the right auricle, and its proximity to the cancerous parotid tumour, is perhaps no more than primary venous cancer, (Rokitansky, Path. Anat., Bd. ii. s. 657,) which by the accidental circumstance of its position had been able to grow to so large a size, and to destroy life mechanically without losing its original, pedunculated, globular form. Next-or if the description be most strictly confined to the heart, these would illustrate the earliest form, for in no way are they the result of the further development of the form just noticed-come Dr. Sims' third case, (Med.-Chir. Trans., vol. xviii. p. 296,) and the tumours at the apex of the ventricle 
in the case now under consideration.' In Dr. Sims' case all the disease was, "in the appendix to the right auricle, a mass of adventitious deposit the size of a small walnut," which the context does not allow us to consider as anything but cancerous. The tumours at the apex in the present case, with their round form, and their sole connection by a narrow pedicle either with the endocardium or with the fibres of encephaloid matter which were interlaced with the carneæ columnæ, bore so close a resemblance to ordinary globular vegetations, that, but for the remainder of the growth, it might have been difficult to decide upon their exact nature.

Mr. Hewett's first case, as far as the brief notice in the Medical Gazette will allow me to infer, stands next as illustrating the mode in which these masses increase in volume, the same being also discernible in the tumours near the base of the heart in the present case; for here the analogy ceases between these growths and globular vegetations, a pendulous lobular mass supplying the place of the round body before seen, and infiltrated cancer of the muscular substance of the heart spreading from the widened base of the tumour which originated in the endocardium. 